\title{
Ladrilho hidráulico para pavimentação de calçada: estudo do traço e da
}

\section{espessura da camada superficial}

\author{
Alessandro Gomes dos Santos ${ }^{1}$, \\ Elaine Guglielmi Pavei Antunes ${ }^{2}$,
}

\begin{abstract}
Resumo: Os ladrilhos hidráulicos são pisos de concreto utilizados para pavimentação de calçadas, composta por duas ou mais camadas, produzidos com aglomerante hidráulico e agregados. O objetivo deste trabalho, busca, analisar a influência do traço e da camada superficial no desempenho das peças produzidas, através de ensaios solicitados pelas normas vigentes. Os agregados utilizados na mistura foram submetidos a ensaio de teor de umidade e granulometria. $\mathrm{O}$ aglomerante utilizado tratou-se do cimento Portland de alta resistência inicial. A produção dos ladrilhos foi realizada com a utilização de formas com medidas previamente definidas e utilização de mesa vibratória para moldagem. Neste estudo foi analisado a variação do traço e espessura da camada superficial de ladrilhos hidráulicos, sendo elas, submetidas a ensaios de módulo de flexão, análise dimensional e desgaste por abrasão, seguindo respectivamente a NBR 9457:2013, NBR 13818:1997 e NBR 9781:2013. Os ladrilhos hidráulicos produzidos, obtiveram um desempenho satisfatório e esperado em relação ao desgaste por abrasão, com resultados dentro das recomendações normativas. Quando solicitados ao ensaio de resistência à flexão, não houve relação dos resultados conforme as variações de produção realizadas, obtendo desempenho insatisfatório e abaixo dos requisitos recomendado pela NBR 9457:2013.
\end{abstract}

Palavras-chave: abrasão; piso de concreto; peças de concreto.

\section{Hydraulic tile for paving sidewalks: Trace study and the thickness of the surface layer}

\begin{abstract}
Hydraulic tiles are concrete floors used for paving sidewalks, consisting of two or more layers, produced with hydraulic binder and aggregates. The objective of this work is to analyze the influence of the trace and the surface layer on the performance of the parts produced, through tests requested by the current standards. The aggregates used in the mixture were submitted to moisture content and granulometry tests. The binder used was Portland cement with high initial strength. The production of the tiles was performed with the use of forms with previously defined measures and use of vibratory table for molding. In this study was analyzed the variation of the trace and thickness of the surface layer of hydraulic tiles, which were subjected to tests of bending module, dimensional analysis and wear by abrasion, following respectively NBR 9457:2013, NBR 13818:1997 and NBR 9781:2013. The hydraulic tiles
\end{abstract}

\footnotetext{
${ }^{1}$ Acadêmico de Engenharia Civil, Universidade do Extremo Sul Catarinense.

${ }^{2}$ Professora Dra.do Curso de Engenharia Civil da UNESC, elainegpa@ unesc.net.
} 


\section{Revista Técnico-Cientifica de Engenharia Civil CIVILTEC}

produced, obtained a satisfactory and expected performance in relation to wear by abrasion, with results within the normative recommendations. When requested to the bending test, there was no relation of the results according to the production variations performed, obtaining unsatisfactory performance and below the requirements recommended by NBR 9457:2013.

Key-words: abrasion; concrete floor; concrete parts.

\section{Introdução}

As calçadas são de uso exclusivo de pedestres e que, por tal, naturalmente, tem divergências de gosto, necessidades e diferenças no modo de locomoção. Com isso, as pavimentações externas, direcionadas a calçadas, devem atender de forma generalista aos requisitos e necessidade dos pedestres que a utilizam em seu cotidiano. A qualificação dos espaços públicos promove a adequação da cidade, bem como o convívio e circulação das pessoas, sobretudo o desempenho das calçadas, pois pode oferecer maior acessibilidade e transformar a atividade de locomoção mais agradável (PINHEIRO, 2014).

A norma de acessibilidade NBR 9050:2020 enfatiza que os pisos devem ter superfície regular, firme, estável e que seja antiderrapante, com intuito de não provocar trepidação em dispositivos com rodas. Também recomenda evitar a estampa dos pisos que causam sensação de insegurança, como desenhos tridimensionais. A norma ainda repassa que as características adotadas, quando for projetar e executar calçadas para acesso público, devem ser providas de rampas com inclinação máxima de $8,33 \%$ e a utilização de pisos tátil de alerta e direcional nas calçadas nos locais apropriados.

Nesse contexto, vem ganhando espaço o uso de ladrilhos hidráulicos como pavimentação em calçadas. Esses componentes podem ser utilizados em diversos locais, tendo em vista que propiciam estabilidade e segurança aos usuários. Os ladrilhos podem ser empregados em forma decorativa (com diversos tipos de pigmentos) ou em formato monocromático, com superfície lisa ou com relevo.

A função do ladrilho hidráulico quando utilizado em pavimentação externa, efetivamente como calçada para pedestre, consiste em resistir aos esforços verticais e ao desgaste por abrasão devido ao tráfego de pessoas, além de atender aos requisitos de 


\section{Revista Técnico-Cientifica de Engenharia Civil CIVILTEC}

acessibilidade conforme NBR 9050: 2020. Os ladrilhos devem atender também as especificações de produção e desempenho de acordo com a NBR 9457:2013, sendo as principais: dimensões geométricas e resistência mecânica.

Os ladrilhos hidráulicos são definidos, segundo Catoia e Liborio (2009) e a NBR 9457:2013, como peça de concreto com formato paralelepipédico, constituída de duas ou mais camadas, com sua superfície exposta ao tráfego de forma lisa ou em baixo-relevo. A composição do ladrilho hidráulico ocorre em duas camadas, sendo uma camada superficial chamada pelos produtores de "nata" e uma segunda camada chamada de "farofa". Os materiais utilizados nas respectivas camadas podem se diferenciar no tipo de cimento e agregados, por se tratarem de camadas que desempenham funções distintas entre si. As melhores práticas para execução do sistema de pavimentação, com uso dos ladrilhos hidráulicos, indicam que eles devem ser assentados com argamassa colante sobre uma base de contrapiso previamente executada.

Marques (2012) relata que o referencial bibliográfico referente a produção de ladrilhos hidráulicos é escasso, ressaltando que tal fato ocorre devido a forma que são produzidos esses componentes, pois trata-se tradicionalmente de um processo artesanal e os conhecimentos sobre a produção são muitas vezes mantidos em sigilo pelos produtores. Devido à escassez de estudo relacionado ao tema, a maioria das produções de ladrilhos hidráulicos, atualmente, são realizadas de forma empírica e os locais de fabricação, muitas vezes não obtêm de suporte necessário e de acompanhamento técnico para obter maior controle de produção e qualidade das peças. Ainda, segundo Marques "O que se destaca, é a dimensão artesanal do trabalho, em que as peças são feitas uma a uma, do início ao fim pelo mesmo profissional, resultando cada uma delas em uma realização única" (MARQUES, 2012).

Nesse contexto, a presente pesquisa visa estudar a influência do traço e da espessura da camada superficial do ladrilho hidráulico no atendimento aos requisitos da NBR 9457:2013 e no ensaio de abrasão determinado pela NBR 9781:2013.

\section{Materiais e métodos}




\section{Revista Técnico-Cientifica \\ de Engenharia Civil CIVILTEC}

Essa pesquisa dividiu-se em cinco etapas, sendo que a primeira delas consistiu na revisão e busca bibliográfica, onde se buscou referencias de procedimentos experimentais e definições de traços. A segunda etapa, referiu-se na caracterização dos agregados (areia fina, areia grossa e o pedrisco).

Para caracterização dos agregados analisou-se os resultados com base na NBR 7211:2009 - Agregado para concreto - Especificação. Foi realizado o ensaio de composição granulométrica, conforme a NBR NM 248:2003, o de teor de umidade do agregado miúdo e graúdo através da DNER-ME 196/98. Os ensaios de caracterização aconteceram no laboratório de materiais de construção civil (LMCC) / IDT/UNESC.

$\mathrm{Na}$ terceira etapa realizou-se o estudo de traço, onde foi estabelecido o traço referência (usual em fábrica), com base no teor de umidade dos agregados e na dosagem empírica dos fabricantes do ladrilho hidráulico da região do sul do Estado de Santa Catarina. Definiu-se dois modelos de produção das peças, o Modelo A e o Modelo B. O Modelo A apresentava $10 \mathrm{~mm}$ de espessura da camada superficial, enquanto o Modelo B apresentava $5 \mathrm{~mm}$, conforme pode ser visualizado na Figura 1, considerando que a NBR 9457:2013 aceita essa variabilidade. Para cada modelo executou-se três tipos de traços para a camada superficial, sendo eles denominados como: traço de referência, traço rico e traço pobre.

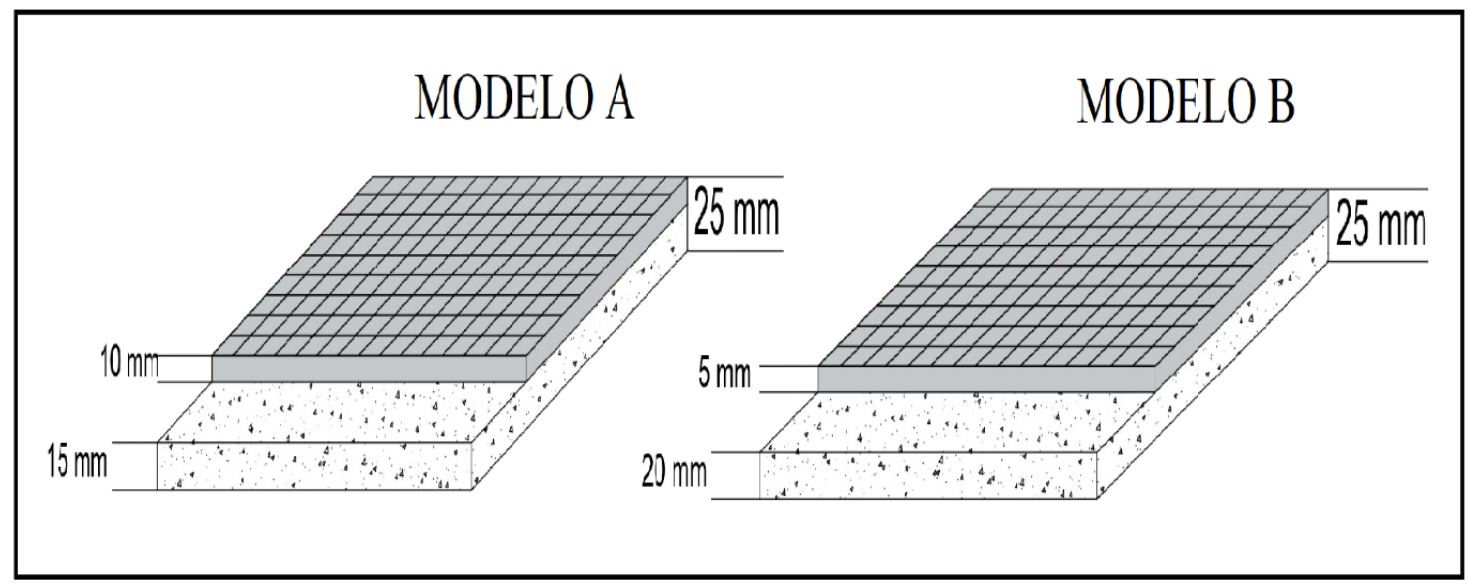

Figura 1. Detalhe espessuras da camada superior

Os traços de referência utilizados para camada superficial e inferior estão representados na Tabela 1. 


\section{Revista Técnico-Cientifica de Engenharia Civil CIVILTEC}

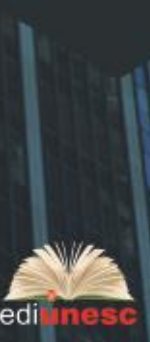

Tabela 1. Traço unitário referência

\begin{tabular}{cccccc}
\hline Camada & Cimento $(\mathrm{Kg})$ & $\begin{array}{c}\text { Areia fina } \\
(\mathrm{Kg})\end{array}$ & $\begin{array}{c}\text { Areia Grossa } \\
(\mathrm{Kg})\end{array}$ & $\begin{array}{c}\text { Pedrisco } \\
(\mathrm{Kg})\end{array}$ & Água $(\mathrm{Kg})$ \\
\hline Superficial & 1,00 & 2,96 & - & - & 0,74 \\
Inferior & 1,00 & - & 4,24 & 4,63 & 0,54 \\
\hline
\end{tabular}

A camada superficial é responsável pela resistência ao desgaste por abrasão, enquanto a camada inferior é responsável por absorver os esforços mecânicos. Desta forma, cada camada possui um traço usual diferente, uma vez que, na camada superficial é utilizado o cimento CP V-ARI-RS, agregado miúdo (areia fina) e água, resultando em uma "nata" cimentícia com maior fluidez. A camada inferior é constituída pelo mesmo tipo de cimento, no entanto é composta por agregado miúdo (areia grossa), agregado graúdo (pedrisco) e água. A camada inferior abrange maior volume da peça, devido a sua maior espessura. A camada inferior, comumente, é chamada pelos produtores de "farofa" cimentícia, pois trata-se de uma composição de menor fluidez, consistência seca e com maior porosidade, fator que influencia na união da camada inferior com a camada superficial.

Para estudar-se o traço da camada superficial, definiu-se o traço de referência como o traço utilizado pelas empresas da região, apresentado na Tabela 1, e mantendo-se a relação água/materiais seco deste traço definiu-se os outros dois traços (traço rico e traço pobre), como pode ser visualizado na Tabela 2.

Tabela 2. Novos traços unitários da camada superficial

\begin{tabular}{cccc}
\hline Camada & Cimento $(\mathrm{Kg})$ & $\begin{array}{c}\text { Areia fina } \\
(\mathrm{Kg})\end{array}$ & Água $(\mathrm{Kg})$ \\
\hline Traço pobre & 1,00 & 3,50 & 0,85 \\
Traço rico & 1,00 & 2,42 & 0,64 \\
\hline
\end{tabular}

O critério para essas variações foi no ponto de vista econômico, tendo em vista que a alteração de dosagem influencia na quantidade de cimento Portland, sendo este o componente de maior custo.

Em resumo, a Tabela 3 apresenta a quantidade de Amostras e suas variáveis. 


\section{Revista Técnico-Cientifica de Engenharia Civil CIVILTEC}

Tabela 3. Produção das peças em função da variação de espessura da camada superior

\begin{tabular}{lcc}
\hline & $\begin{array}{c}\text { Espessura da camada } \\
\text { superior de } 0,5 \mathrm{~cm}\end{array}$ & $\begin{array}{c}\text { Espessura da camada } \\
\text { superior de } 1,0 \mathrm{~cm}\end{array}$ \\
\hline Amostra A & Traço Ref. & Traço Ref. \\
Amostra B & Traço pobre & Traço pobre \\
Amostra C & Traço rico & Traço rico \\
\hline
\end{tabular}

Na quarta etapa realizou-se a dosagem e moldagem dos ladrilhos hidráulicos, sendo que, o processo de produção dos ladrilhos hidráulicos aconteceu em parque fabril e, por conseguinte, foram utilizados os equipamentos e materiais disponibilizados no local - controlados tecnologicamente. Os ladrilhos foram previamente moldados em fôrmas com medidas preestabelecidas, preparadas inicialmente com o uso de desmoldante. Foi empregado mesa vibratória para o adensamento do concreto no molde e para evitar bolhas no acabamento final. As dosagens foram realizadas com a utilização de balança e a mistura preparada em betoneira. A Figura 2 apresenta a área de trabalho e equipamentos usados na fabricação.

(a)

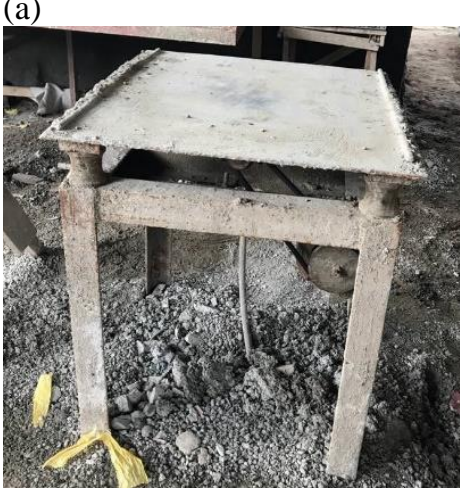

(d)

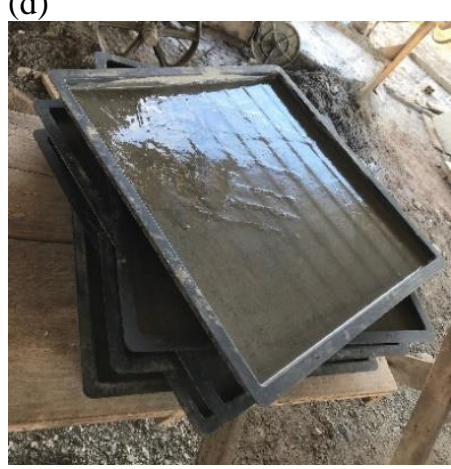

(b)

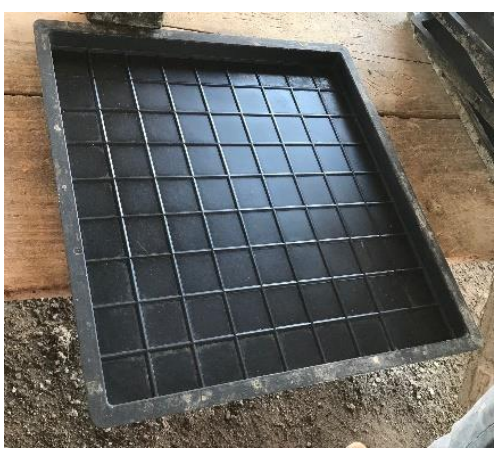

(e)

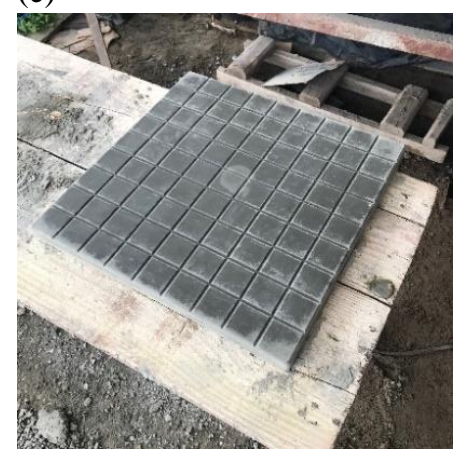

(c)

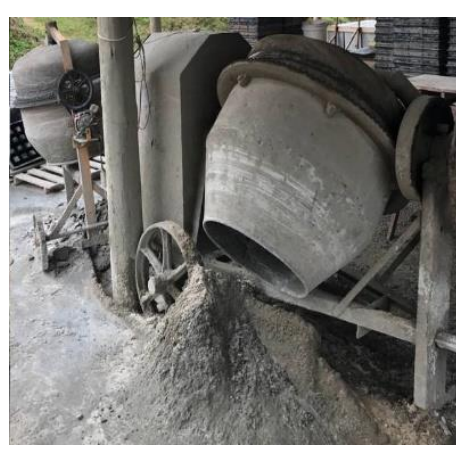

(f)

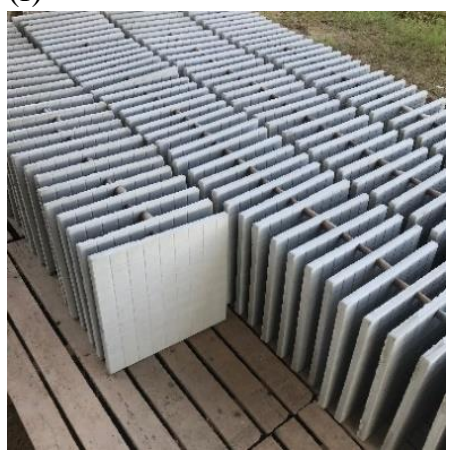

Figura 2. Equipamentos utilizados (a) mesa vibratória (b) molde utilizada (c) betoneira utilizada (d) camada superficial na forma (e) ladrilho recém desmoldado (f) processo de cura ao ar livre 


\section{Revisto Téenico-Cientifica \\ de Engenharia Civil CIVILTEC}

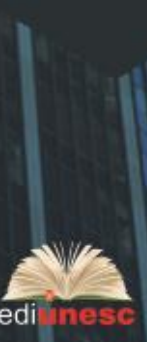

Diante da apresentação das variáveis que foram definidas, a quinta e última etapa, consistiram na verificação dos ladrilhos hidráulicos produzidos, no atendimento a NBR 9457:2013, norma específica do ladrilho hidráulico e na verificação da resistência à abrasão de acordo com a NBR 9781:2013 - peças de concreto para pavimentação - especificação e métodos de ensaio, respectivamente.

Para a análise dimensional, conforme orientação da NBR 9457:2013, verificou-se a pertinência com os moldes utilizados, analisando a qualidade superficial das peças, bem como, suas dimensões preestabelecidas. Foram fabricados 24 ladrilhos hidráulicos de 450 x $450 \mathrm{~mm}$ com $25 \mathrm{~mm}$ de espessura, essas medidas foram conferidas através de paquímetro com precisão de $0,1 \mathrm{~mm}$ e régua metálica com precisão de $1 \mathrm{~mm}$, após a o processo de produção e cura com 28 dias.

A análise visual e dimensional foi realizada em todos os ladrilhos fabricados e seguindo as diretrizes estabelecidas pela NBR 9457:2013, sendo eles: as dimensões, chanfro e baixorelevo, arestas, empenamento, esconsidade, ortogonalidade e inspeção visual. A Figura 3 apresenta a análise visual e dimensional.

(a)

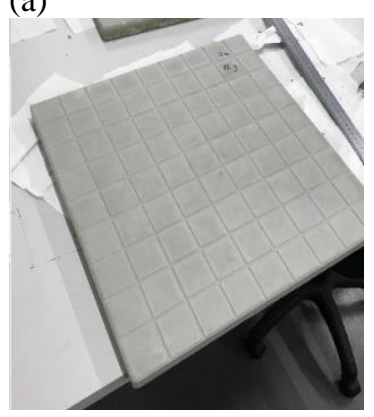

(b)

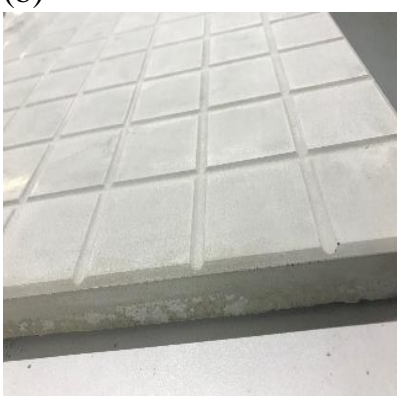

(c)

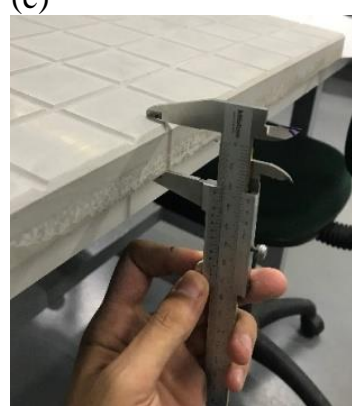

Figura 3. Análise visual e dimensional das peças prontas (a) inspeção visual (b) conferencia de bordas, arestas e acabamento (c) análise dimensional com paquímetro.

O ensaio de flexão das peças de ladrilho hidráulico foi realizado seguindo a NBR 13818:1997, conforme indicação da NBR 9457:2013 que exige resultados mínimos para a resistência característica a flexão maior ou igual a 3,5 MPa. Foram utilizadas as placas com suas dimensões inteiras, sendo solicitadas a flexão por três apoios com velocidade de carregamento controlada, seguindo as prescrições da NBR 13818:1997. A distância entre os 


\section{Revisto Téenico-Cientifica \\ de Engenharia Civil CIVILTEC}

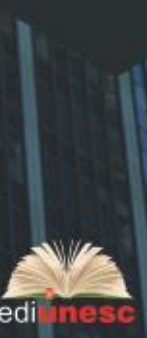

apoios foi de $400 \mathrm{~mm}$ e a ruptura no terço central da placa. A Figura 4 apresenta a execução do ensaio à flexão do ladrilho hidráulico.

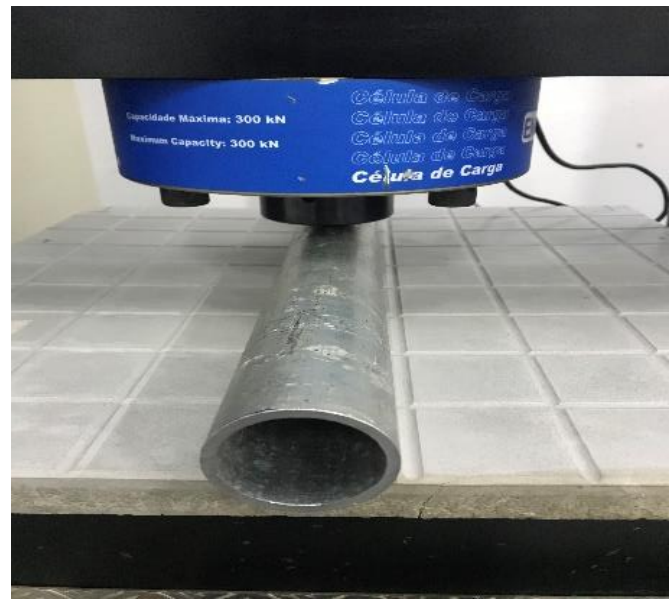

Figura 4. Ensaio de flexão

Para determinação dos resultados utilizou as equações de carga de ruptura e módulo de resistência à flexão, conforme apresentado pela NBR 13818:1997.

Para determinar a resistência ao desgaste por abrasão nas placas de ladrilho hidráulico, foi seguido a NBR 9781:2013. Utilizou peças de 10 x $10 \mathrm{~cm}$ cortada a partir das peças inteiras de 450 x $450 \mathrm{~mm}$ e $25 \mathrm{~mm}$ de espessura. $\mathrm{O}$ ensaio consiste na utilização de um dispositivo de abrasão, um disco rotativo de aço com diâmetro de $200 \mathrm{~mm}$ e espessura de $70 \mathrm{~mm}$, sendo utilizado um funil para abastecimento de material abrasivo, composto de óxido de alumínio fundido branco grana F80. A pressão do corpo de prova contra o disco é determinada pela calibração padrão do equipamento, sendo ajustada de maneira que após 75 rotações em $60 \mathrm{~s}$, seja produzida uma cavidade de aproximadamente $17 \mathrm{~mm}$ de comprimento.

A obtenção dos resultados é através da medição da cavidade produzida pelo disco abrasivo, com o auxílio de linhas guias e utilização de paquímetro e régua metálica medidas em milímetros. A NBR 9781:2013 estabelece os limites dos resultados obtidos no ensaio, sendo que para tráfego de pedestres, veículos leves e veículos comerciais de linha, deve ter uma cavidade máxima menor ou igual a $23 \mathrm{~mm}$. 


\section{Revista Técnico-Cientifica de Engenharia Civil CIVILTEC}

(a)

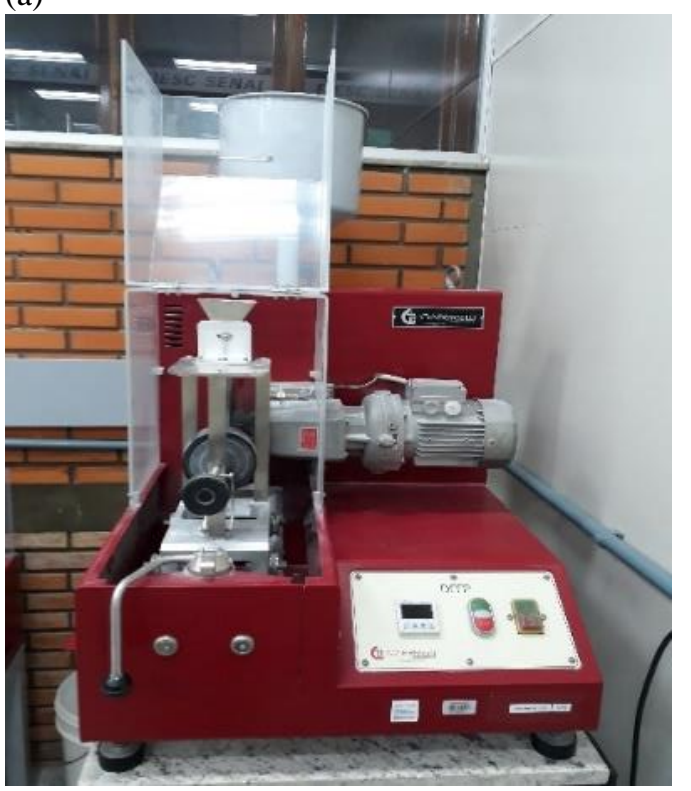

(b)

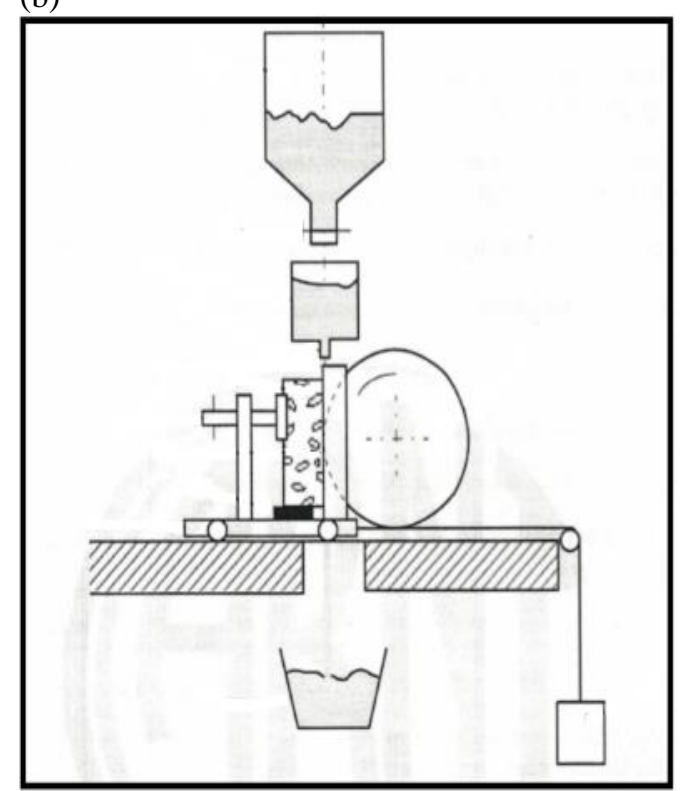

Figura 5. Equipamento utilizado para o ensaio de desgaste por abrasão. (a) equipamento de abrasão (b) detalhe do ensaio de abrasão conforme a NBR 9781:2013

O ensaio foi realizado no laboratório de cerâmica e construção civil do SENAI/SC, devido ser o local mais próximo a realizar esse ensaio e, por tal complexidade, essa verificação foi realizada apenas para uma amostra, com traço e espessura definido pelos resultados obtidos no ensaio de resistência à flexão.

\section{Resultados e discussões}

Na Tabela 4 são apresentados os resultados de teor de umidade, módulo de finura e diâmetro máximo dos agregados coletados na fábrica e utilizados para produção dos ladrilhos.

Tabela 4. Teor de umidade dos agregados

\begin{tabular}{cccc}
\hline Agregado & Teor de umidade $(\%)$ & Módulo de finura $(\%)$ & $\begin{array}{c}\text { Diâmetro máximo } \\
(\mathrm{mm})\end{array}$ \\
\hline Areia fina & 1,35 & 2,10 & 0,60 \\
Areia grossa & 2,00 & 3,17 & 4,75 \\
Pedrisco & 1,18 & - & 9,5 \\
\hline
\end{tabular}




\section{Revista Técnico-Cientifica de Engenharia Civil CIVILTEC}

No gráfico da Figura 6 está representado visualiza-se a curva granulométrica dos agregados.

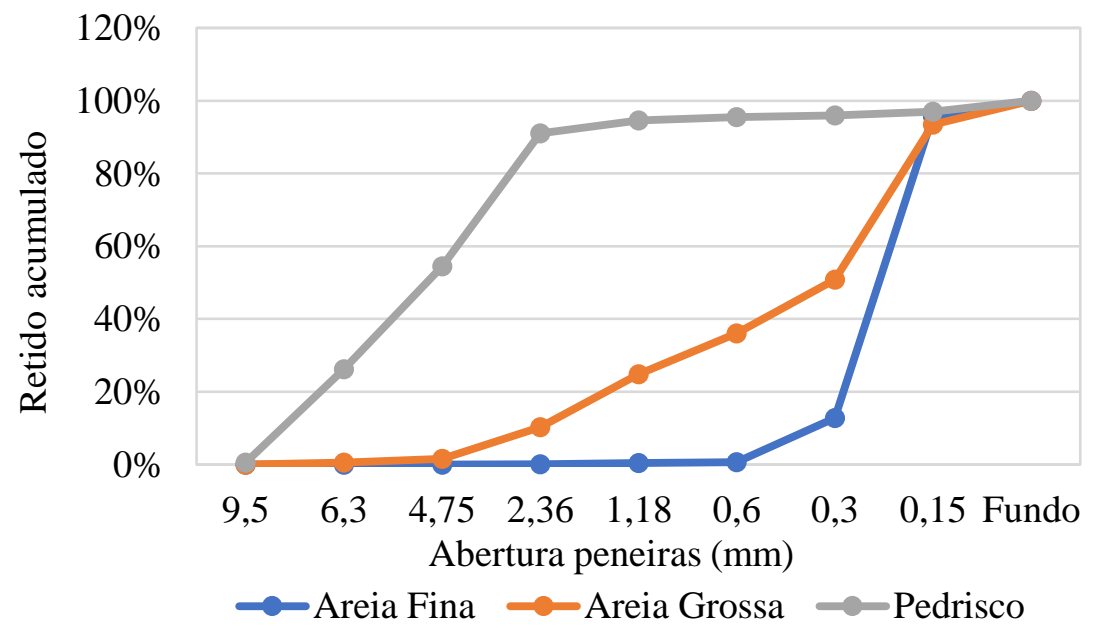

Figura 6. Distribuição granulométrica

Com base na composição granulométrica dos agregados utilizados pode-se afirmar que a areia fina e a areia grossa atendem aos limites da zona utilizável prescritos pela NBR 7211:2009. E, o pedrisco, considerado como agregado graúdo, que está na zona granulométrica 4.75/12.5, sendo d/D, onde é correspondente à menor (d) e a maior (D) dimensões do agregado graúdo, também satisfaz as diretrizes da NBR 7211:2009.

A Tabela 5 e 6 apresentam os resultados obtidos no ensaio de resistência a flexão com a camada superficial de 0,5 e 1,0 centímetro, respectivamente.

Tabela 5. Resultados Resistencia a flexão com camada superior de 0,5 centímetro

\begin{tabular}{|c|c|c|c|c|c|}
\hline $\begin{array}{l}\text { Espessura camada } \\
\text { superior }(\mathrm{cm})\end{array}$ & Traço & $\begin{array}{l}\text { Resistência à flexão } \\
\text { (MPa) }\end{array}$ & Mediana & Média & $\begin{array}{l}\text { Desvio } \\
\text { padrão }\end{array}$ \\
\hline \multirow[t]{11}{*}{ 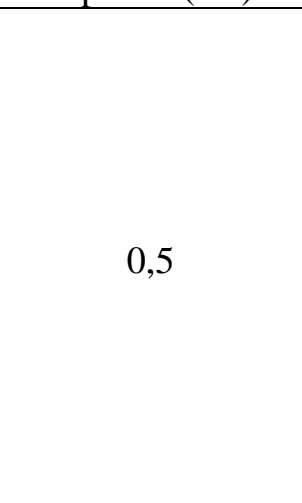 } & \multirow{4}{*}{ Ref. } & 3,39 & \multirow{4}{*}{3,36} & \multirow{4}{*}{3,26} & \multirow{4}{*}{0,24} \\
\hline & & 3,32 & & & \\
\hline & & 2,90 & & & \\
\hline & & 3,42 & & & \\
\hline & \multirow{3}{*}{ Pobre } & 3,10 & \multirow{3}{*}{3,10} & \multirow{3}{*}{2,81} & \multirow{3}{*}{0,51} \\
\hline & & 3,11 & & & \\
\hline & & 2,22 & & & \\
\hline & \multirow{4}{*}{ Rico } & 1,36 & \multirow{4}{*}{1,82} & \multirow{4}{*}{1,88} & \multirow{4}{*}{0,60} \\
\hline & & 2,54 & & & \\
\hline & & 1,39 & & & \\
\hline & & 2,24 & & & \\
\hline
\end{tabular}




\section{Revista Técnico-Cientifica de Engenharia Civil CIVILTEC}

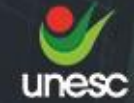

Engenharia Civil

Tabela 6. Resultados Resistencia a flexão com camada superior de 1,0 centímetro

\begin{tabular}{|c|c|c|c|c|c|}
\hline $\begin{array}{c}\text { Espessura camada } \\
\text { superior }(\mathrm{cm}) \\
\end{array}$ & Traço & $\begin{array}{l}\text { Resistência à flexão } \\
(\mathrm{MPa})\end{array}$ & Mediana & Média & $\begin{array}{l}\text { Desvio } \\
\text { padrão }\end{array}$ \\
\hline \multirow{10}{*}{1,0} & \multirow{3}{*}{ Ref. } & 3,56 & \multirow{3}{*}{3,42} & \multirow{3}{*}{3,39} & \multirow{3}{*}{0,18} \\
\hline & & 3,42 & & & \\
\hline & & 3,20 & & & \\
\hline & \multirow{4}{*}{ Pobre } & 2,34 & \multirow{4}{*}{2,45} & \multirow{4}{*}{2,49} & \multirow{4}{*}{0,18} \\
\hline & & 2,74 & & & \\
\hline & & 2,48 & & & \\
\hline & & 2,41 & & & \\
\hline & \multirow{3}{*}{ Rico } & 2,78 & \multirow{3}{*}{2,65} & \multirow{3}{*}{2,57} & \multirow{3}{*}{0,26} \\
\hline & & 2,28 & & & \\
\hline & & 2,65 & & & \\
\hline
\end{tabular}

Com base na análise dos resultados de resistência à flexão, através da análise de variância (ANOVA) com intervalo de confiança de 95\%, pode-se afirmar que referente ao ensaio de flexão a variação da espessura da camada superficial de 0,5 e 1,0 cm, não interfere nos resultados. As variações podem ser observadas nos gráficos das Figuras 7 e 8.

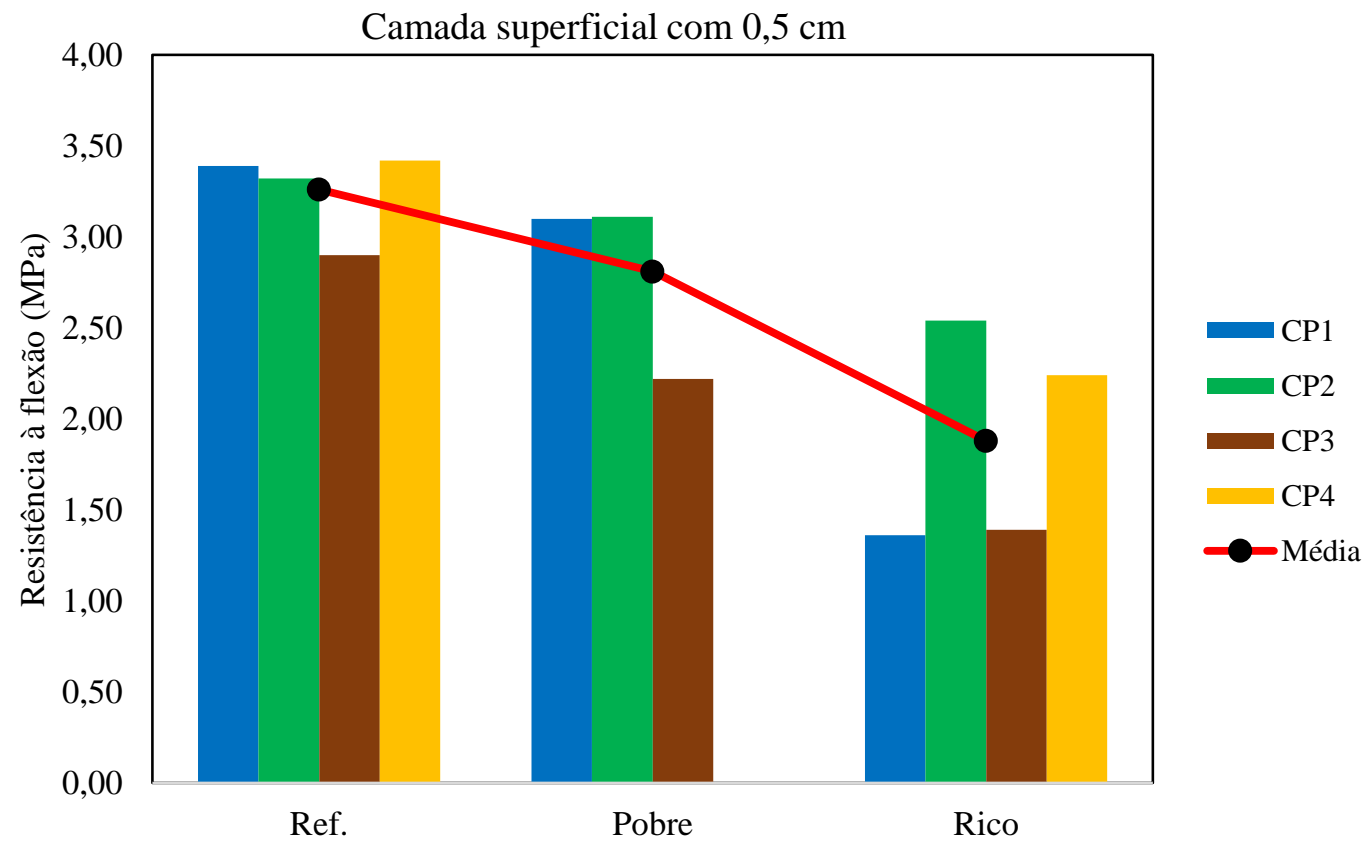

Figura 7. Resistencia à flexão em função da camada superficial de $0,5 \mathrm{~cm}$.

Em relação aos diferentes traços, as análises estatísticas apontam diferença do traço rico, para as amostras com $0,5 \mathrm{~cm}$ de espessura, quando comparado ao traço de referência e ao traço 


\section{Revista Técnico-Cientifica de Engenharia Civil CIVILTEC}

pobre. No entanto, visualiza-se que no traço rico com $0,5 \mathrm{~cm}$ de espessura tem-se o maior valor de desvio padrão em relação aos outros dois traços, isso devido a dois CPs apresentarem menores resistência quando comparados aos outros dois CPs. Por conseguinte, os autores consideram ser necessário a realização de novos testes neste âmbito para melhor discussão desse resultado.

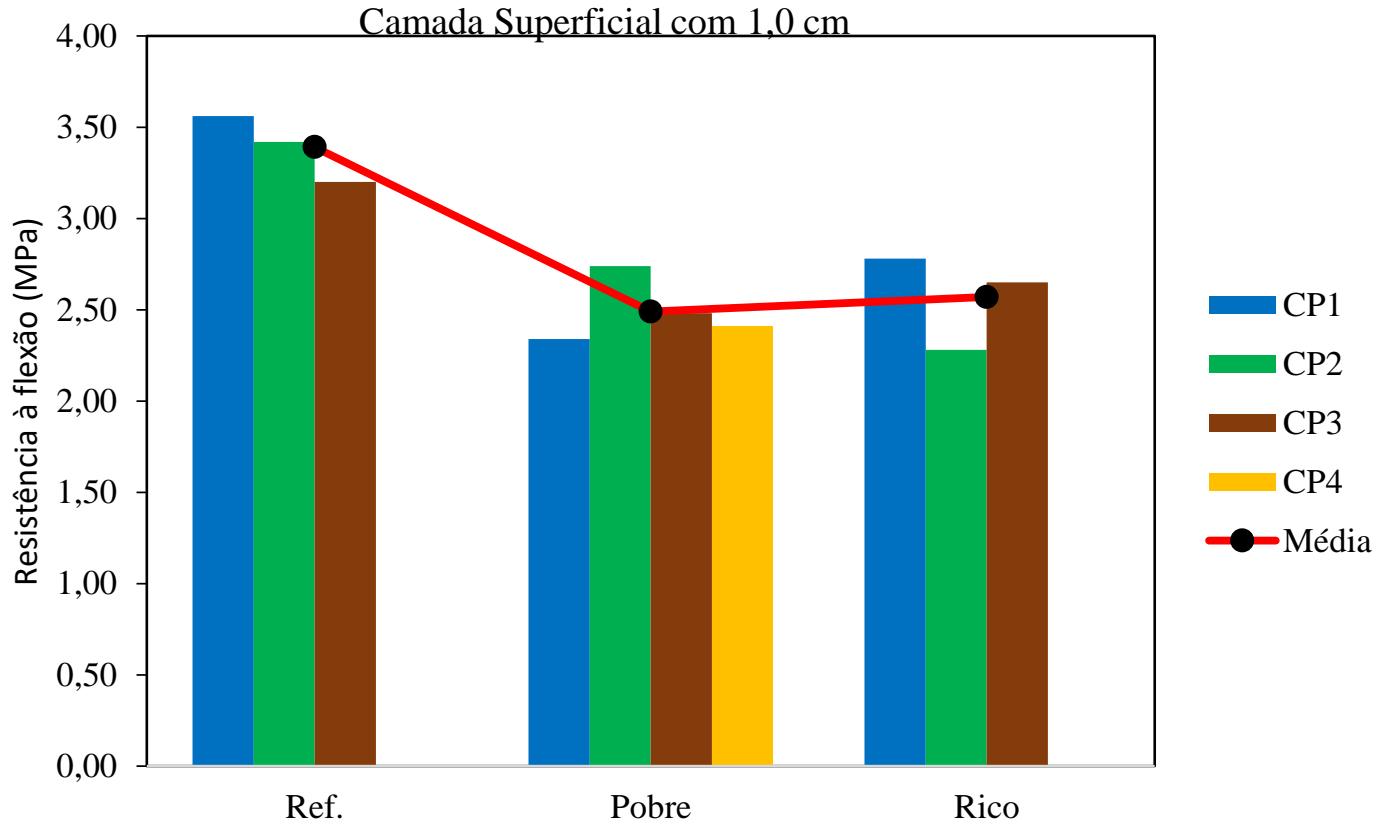

Figura 8. Resistencia à flexão em função da camada superficial de 1,0 cm.

A Figura 9 apresenta o gráfico boxplot dos resultados médios de resistência a flexão em função das espessuras de 0,5 e 1,0 cm. Pode-se afirmar, através da ANOVA, que não existe diferença estatística entre os valores de resistência à flexão em função das espessuras estudadas. Tal fato deve-se devido as variações de espessura terem sido aplicadas na camada superior dos ladrilhos hidráulicos e, que, portanto, não influenciaram consideravelmente nos resultados de resistência a flexão. A principal região solicitada no ensaio de flexão é a camada inferior e, uma vez que, está camada não foi alterada nas amostras ensaiadas não se verificou diferenças estatísticas. 


\section{Revisto Térico-Cientifica de Engenharia Civil CIVILTEC}

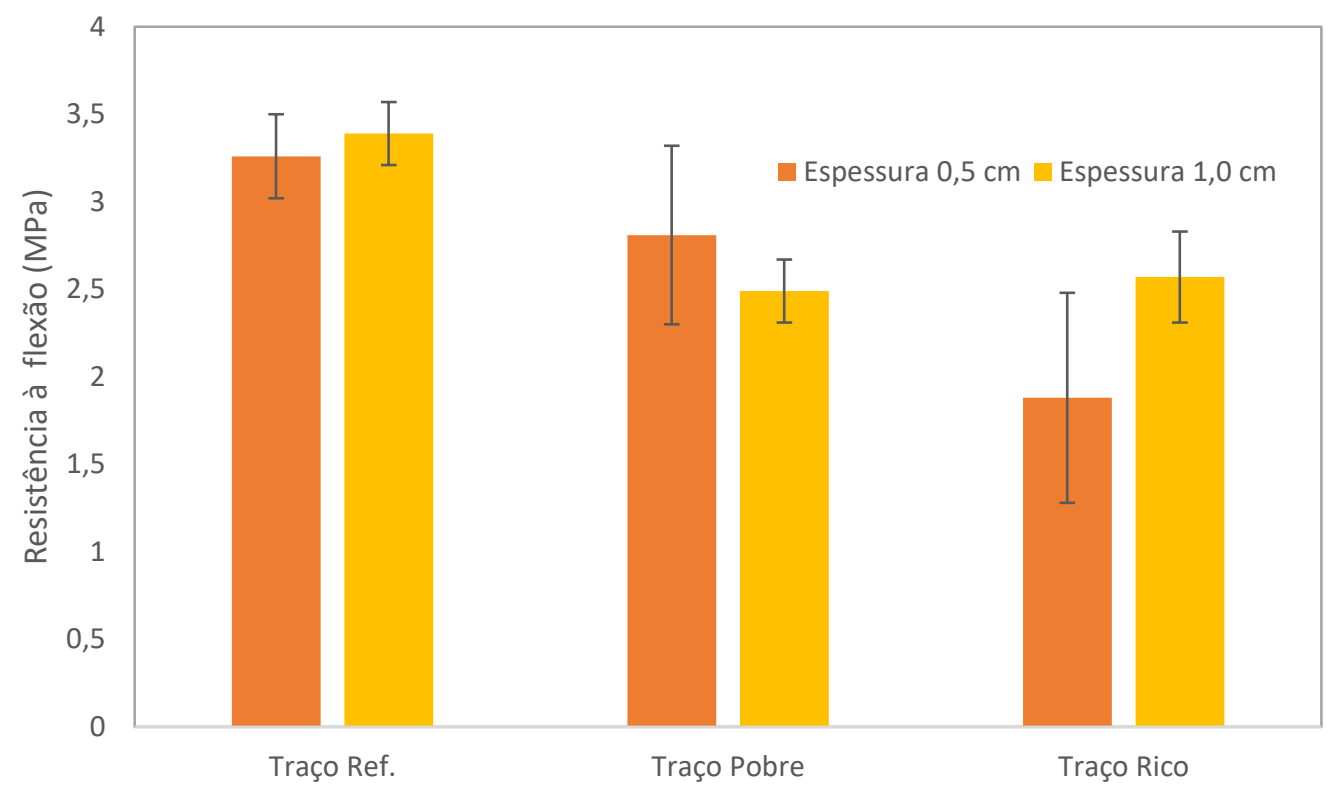

Figura 9. Gráfico dos resultados de resistência de flexão em relação as variações de espessura e traços.

Cabe mencionar que o valor mínimo de resistência característica à flexão preconizado pela NBR 9457:2013 é de 3,5 MPa não foi alcançado em nenhuma das amostras. Na pesquisa de Marques (2012) obtiveram-se resultados próximos a este trabalho, sendo que seu corpo de prova de referência apresentou uma resistência de 3,86 MPa e as demais variações, onde se utilizou pó de basalto e areia de resíduos de construção e demolição (RCC), apresentaram resistências de 3,27 MPa e 4,25 MPa, respectivamente. Já, na pesquisa de Catoia e Liborio (2009), os valores de resistência à flexão foram de aproximadamente, em média, 8,00 MPa, no entanto, eles utilizaram o cimento CP V ARI RS e o cimento CP B 40 Estrutural, pois o objetivo desta pesquisa era de produzir ladrilhos com concreto de alto desempenho.

O ensaio de desgaste por abrasão, conforme a NBR 9781:2013, foi realizado apenas na amostra que apresentou melhor resultado no ensaio de resistência à flexão, logo, na amostra com $1,0 \mathrm{~cm}$ de espessura e com a camada superficial de traço rico. Os resultados desse ensaio estão representados na Tabela 7, conforme laudo apresentado pelo laboratório de cerâmica e construção civil do SENAI/SC. 


\section{Revisto Téenico-Cientifica \\ de Engenharia Civil CIVILTEC}

Tabela 7. Resultados do ensaio de resistência a abrasão conforme NBR 9781:2013

\begin{tabular}{cccc}
\hline & Cavidade $(\mathrm{mm})$ & $\begin{array}{c}\text { Espessura } \\
\text { superficial }\end{array}$ & Traço \\
\hline CP1 & 21 & & RICO \\
CP2 & 22 & $\mathbf{1 , 0}$ & \\
CP3 & 19 & & \\
Média & $\mathbf{2 1}$ & & \\
\hline
\end{tabular}

A NBR 9781:2013 determina que para trafego de pedestres, veículos leves e veículos comerciais de linha, a cavidade máxima devido ao ensaio de abrasão deve ser menor ou igual a $23 \mathrm{~mm}$, com isso, o ladrilho hidráulico selecionado para este ensaio, atendeu os critérios da norma. Catoia e Liborio (2009), realizaram o ensaio de abrasão em suas peças, com base na NBR 12042:1992 - Materiais inorgânicos - determinação do desgaste por abrasão - Método de ensaio, obtendo, segundo os autores, um resultado compatível, porém abaixo do mínimo requerido pela NBR 9781:2013. Reis e Tristão (2010) também utilizaram a NBR 12042:1992 para analisar a resistência à abrasão de suas peças de ladrilho hidráulico e, também não obtiveram resultados que atendessem a NBR 9781:2013, contudo, a relação água/cimento utilizada para o traço de referência dessa pesquisa foi de 0,70 .

Vale destacar que os autores citados fizeram uso de metodologia de produção diferente em relação a este trabalho, além de traços distintos e utilização de norma para realização do ensaio de resistência à flexão também divergente e, com isso, não é possível realizar uma comparação confiável dos resultados, neste quesito, deste trabalho com os autores mencionados. As referências bibliográficas para comparação e análise dos resultados foram escassas.

A inspeção visual das peças de ladrilho hidráulico foi realizada conforme a NBR 9457:2013, onde foram analisadas as 24 peças produzidas. Todas as amostras apresentaram aspectos homogêneo e monocromático, com poucos defeitos e rebarbas, ou imperfeições dentro das tolerâncias estabelecidas, obtendo boa e aceitável qualidade visual e de acabamento. Os demais aspectos dimensionais estabelecidos pela NBR também obtiveram resultados adequado ao prescrito. 


\section{Revista Técnico-Cientifica de Engenharia Civil CIVILTEC}

\section{Conclusões}

Com base na caracterização dos agregados, bem como no processo experimental adotado nessa pesquisa, conclui-se que o objetivo de produzir ladrilhos hidráulicos com uma referência pré-estabelecida, que atendam a NBR 9457:2013 e o ensaio de abrasão estabelecido pela NBR 9781:2013, foi alcançado parcialmente, sendo que, quando as peças foram solicitadas a flexão, não obtiveram os resultados que atendessem o mínimo requerido pela normativa. Conforme análise dos resultados de resistência característica a flexão, afirma-se que a alteração do traço e da espessura de até $1,0 \mathrm{~cm}$ da camada superficial do ladrilho hidráulico, não influenciam nos resultados de resistência a flexão. Com isso, a peça selecionada para o ensaio de abrasão, foi com o traço rico e espessura de 1,0 cm da camada superior, que atendeu aos requisitos da NBR 9781:2013, com um resultado médio de $21 \mathrm{~mm}$.

Em relação a análise dimensional e visual, as peças tiveram resultados compatíveis, com boa qualidade de acabamento, medidas dentro das tolerâncias, chanfro e baixo relevo, arestas vivas, empenamento, esconsidade e ortogonalidade dentro do aceitável.

\section{Referências}

ASSOCIAÇÃO BRASILEIRA DE NORMAS TÉCNICAS. NBR 9457:2013. Ladrilhos hidráulicos para pavimentação - Especificação e métodos de ensaio. Rio de Janeiro, 2013.

ASSOCIAÇÃO BRASILEIRA DE NORMAS TÉCNICAS. NBR 13818:1997. Placas cerâmicas para revestimento - Especificação e métodos de ensaios. Rio de Janeiro, 1997.

ASSOCIAÇÃO BRASILEIRA DE NORMAS TÉCNICAS. NBR 9050:2015. Acessibilidade a edificações, mobiliários, espaços e equipamentos urbanos. Rio de Janeiro, 2015.

ASSOCIAÇÃO BRASILEIRA DE NORMAS TÉCNICAS. NBR 7211:2009. Agregado para concreto - especificação. Rio de Janeiro, 2009.

ASSOCIAÇÃO BRASILEIRA DE NORMAS TÉCNICAS. NBR NM 248:2003. Agregados Determinação da composição granulométrica. Rio de Janeiro, 2003.

ASSOCIAÇÃO BRASILEIRA DE NORMAS TÉCNICAS. NBR 9781:2013. Peças de concreto para pavimentação - Especificação e métodos de ensaio. Rio de Janeiro, 2013.

ASSOCIAÇÃO BRASILEIRA DE CIMENTO PORTLAND - ABCP. Manual de ladrilho hidráulico. São Paulo, 2010. 


\section{Revisto Téenico-Cientifica de Engenharia Civil CIVILTEC}

ALMEIDA, Eridiana Pizzinatto; GIACOMINI, Larissa Bressan; BORTOLUZZI, Marluse Guedes. Mobilidade e Acessibilidade Urbana. Passo Fundo, p.1-7, nov. 2013.

CATOIA, Thiago; LIBORIO, Jefferson Benedicto Libardi. SUBSÍDIOS PARA PRODUÇÃO DE LADRILHOS E REVESTIMENTOS HIDRÁULICOS DE ALTO DESEMPENHO. Cadernos de Engenharia de Estruturas, São Carlos, v. 11, n. 53, p.129$133,2009$.

CATOIA, Thiago; LIBORIO, Jefferson Benedicto Libardi. LADRILHOS E REVESTIMENTOS HIDRÁULICOS DE ALTO DESEMPENHO. Cadernos de Engenharia de Estruturas, São Carlos, v. 10, n. 47, p.53-74, 2008.

CATOIA, Thiago. Ladrilhos e revestimentos hidráulicos de alto desempenho. 2007. 111 p. Dissertação (Mestrado) - Programa de Mestrado em Engenharia Civil, Escola de Engenharia de São Carlos da Universidade Federal de São Paulo, São Carlos, 2007.

DEPARTAMENTO NACIONAL DE ESTRADAS DE RODAGEM. DNER-ME 196/98: Agregados determinação do teor de umidade total, por secagem, em agregado graúdo. Departamento Nacional de Estradas de Rodagem. Rio de Janeiro, RJ. 1998.

FERREIRA, Telma Ellen Drumond et al. Aproveitamento de resíduos finos de rochas ornamentais na fabricação de ladrilho hidráulico piso tátil para a orientação de deficientes visuais. Revista Eletrônica Engenharia de Interesse Social, João Monlevado, v. 1, n. 3, p.1$15,2018$.

MARQUES, J. S. Estudo do processo de produção de ladrilhos hidráulicos visando à incorporação de resíduos sólidos. Programa de Pós-Graduação em Engenharia de Edificações e saneamento. Universidade Estadual de Londrina. Londrina, 2012.

O QUE É DESENVOLVIMENTO SUSTENTÁVEL. Dicionário Ambiental. ((O))eco, Rio de Janeiro, ago.2014. Disponível em: <http://www.oeco.org.br/dicionario-ambiental/28588-oque-e-desenvolvimento-sustentavel/>. Acesso em: 23 de Abril de 2019.

PINHEIRO, Lígia. ASSOCIAÇÃO BRASILEIRA DE CIMENTO PORTLAND - ABCP. Projeto técnico: CALÇADAS ACESSIVEIS. São Paulo, 2014.

REIS, Alessandra Silva; TRISTÃO, Fernando Avancini. Ladrilho hidráulico piso tátil com adição de resíduo de beneficiamento de rochas ornamentais. Ibracon, Vitória, v. 3, n. 4, p.390419, dez. 2010. 